Article

\title{
Research Data Sharing in Spain: Exploring Determinants, Practices, and Perceptions
}

\author{
Rafael Aleixandre-Benavent ${ }^{1, *}$, Antonio Vidal-Infer ${ }^{2}$, Adolfo Alonso-Arroyo ${ }^{2}{ }^{\mathbb{O}}$, \\ Fernanda Peset ${ }^{3}$ and Antonia Ferrer Sapena ${ }^{3}$ (D) \\ 1 Ingenio (CSIC-Universitat Politècnica de València), UISYS (CSIC-Universitat de València), 46003 València, \\ Spain \\ 2 Departament de Historia de la Ciencia y Documentación, Universitat de València, 46010 València, Spain; \\ antonio.vidal-infer@uv.es (A.V.-I.); adolfo.alonso@uv.es (A.A.-A.) \\ 3 DCADHA, Universitat Politècnica de València, 46022 València, Spain; mpesetm@upv.es (F.P.); \\ anfersa@upv.es (A.F.S.) \\ * Correspondence: Rafael.Aleixandre@uv.es
}

Received: 2 March 2020; Accepted: 24 March 2020; Published: 27 March 2020

check for updates

\begin{abstract}
This work provides an overview of a Spanish survey on research data, which was carried out within the framework of the project Datasea at the beginning of 2015. It is covered by the objectives of sustainable development (goal 9) to support the research. The purpose of the study was to identify the habits and current experiences of Spanish researchers in the health sciences in relation to the management and sharing of raw research data. Method: An electronic questionnaire composed of 40 questions divided into three blocks was designed. The three Section s contained questions on the following aspects: (A) personal information; (B) creation and reuse of data; and (C) preservation of data. The questionnaire was sent by email to a list of universities in Spain to be distributed among their researchers and professors. A total of 1063 researchers completed the questionnaire. More than half of the respondents (54.9\%) lacked a data management plan; nearly a quarter had storage systems for the research group; $81.5 \%$ used personal computers to store data; "Contact with colleagues" was the most frequent means used to locate and access other researchers' data; and nearly $60 \%$ of researchers stated their data were available to the research group and collaborating colleagues. The main fears about sharing were legal questions (47.9\%), misuse or interpretation of data $(42.7 \%)$, and loss of authorship (28.7\%). The results allow us to understand the state of data sharing among Spanish researchers and can serve as a basis to identify the needs of researchers to share data, optimize existing infrastructure, and promote data sharing among those who do not practice it yet.
\end{abstract}

Keywords: data sharing; Spanish survey; willingness; drivers; barriers; sustainable research

\section{Background}

Scientific research can be improved through the management and exchange of research data. Sharing data allows creative innovation from archival data sets, the generation of new knowledge and promotion of new discoveries, the formulation of new hypotheses, the creation of new meaning by connecting existing data sets, and the verification of results [1-3]. The principles on which data sharing is based are receiving increasing support from funding agencies due to growing interest in getting the highest possible return on investment, both in terms of the quality of the products derived from research and in the reuse of data [4-6].

Research data are a valuable resource that requires much time and money to be produced. The reuse of research data contributes to the sustainability of research systems by providing a new use for the data that is released. In this sense, the contribution of open data to sustainable development 
goals is undeniable [7]. In particular, the sharing of research data can not only produce more sustainable research, but also accelerate the innovation mentioned in goal 9 of The Sustainable Development Goals of the United Nations (https://www.un.org/sustainabledevelopment/infrastructureindustrialization/): "Build resilient infrastructure, promote inclusive and sustainable industrialization, and foster innovation". Many data have significant value outside of the initial investigation. The virtues of open data and the benefits of sharing them are now firmly established in the literature, despite limited implementation [8-12].

The existing literature states that data-sharing practices in most scientific areas are currently minimal, with researchers being more likely to reserve their data than to share it publicly [13-17]. One of the aspects that should be investigated is what the current practices of Spanish researchers are in this process. To understand and assess these practices, the objective of this survey is to identify the habits and current experiences of Spanish researchers in relation to the management and exchange of raw research data, as well as their motivations for sharing, the circumstances that prevent or make data sharing difficult, and the technical support and infrastructure needed for implementation. We also try to understand the determinants of individual Spanish researchers' motivation to publish their research data, as well as the challenges in accessing, extracting, and using data from open data initiatives.

\section{Methods}

An electronically based questionnaire was designed to collect data about the Spanish researchers' data-sharing experiences and practices. The questionnaire was based on the previous experience of the research team and other validated surveys that have already been performed at universities and research institutions in other countries [14-24]. The questionnaire included 40 items comprising open-ended and multiple-choice questions organized into the following Section s (see Supplementary Materials at the end of Concluding Remarks Section Table 1):

Table 1. Distribution of respondents by area of knowledge $\left({ }^{*}\right)$.

\begin{tabular}{cc}
\hline AREA & N \\
\hline Health Sciences (HS) & 393 \\
\hline Social Sciences (SS) & 315 \\
\hline Arts and Humanities (AH) & 129 \\
\hline Physics and Technology (PT) & 341 \\
\hline TOTAL & 1178
\end{tabular}

$\left.{ }^{*}\right)$ A single respondent might be included in more than one area.

Section A includes questions about personal data and the following variables: age, sex, position, years of active research, name of the centre of research and subject area, i.e., Health Sciences (HS), Social Sciences (SS), Arts and Humanities (AH), and Physics and Technology (PT).

Section $B$ addresses the creation and reuse of data and investigates several topics: the existence of policies or management plans in the institution; the reasons why these were developed or why they do not exist; who in the group is responsible for managing the data; where the data are stored; and what type of data backups are made. The researchers were also asked if they would like to use the unpublished research data of other researchers with whom they were not collaborating and what means could be used to locate them; what external data they usually use; if they had ever been asked for data by other researchers or if they had received an open data request; and any problems or prejudices they had to share.

Section $C$ was designed to investigate data preservation practices after the project was finished: threats that can be derived from sharing data; how to store them to preserve their access and future; appropriate places to preserve them; the existence of plans in the institution for the creation of a data repository for their storage and preservation; the existence in the discipline of guidelines or 
recommendations for preserving data; the importance of preservation; and, finally, if the institution provides help to carry out data management throughout its cycle.

The final wording of the questions and their grouping in each Section was discussed in the working group. After being assessed by the Ethics Review Board of the University of Valencia, the research team decided to include this text in the survey introduction: "The answers collected in this questionnaire do not involve the processing of personal data. Your answers do not allow to identify you and, in those cases in which exceptional circumstances allowed, it is expressly warned. In any case, the researchers undertake not to carry out any type of re-identification". The questionnaires were sent to the Vice Chancellors of Research of Spanish Universities so it could be distributed by email among the members of their university communities. The implementation period was from January 19 to March 31, 2015. The data were statistically analyzed using descriptive and inferential statistics by means of the statistical software SPSS.

\section{Results}

After the distribution of the questionnaires, a total of 1063 individual questionnaires were received. In the following chapters, the results are presented according to the three Section $\mathrm{s}$ in which the 40 survey questions were grouped.

\subsection{Personal Data}

Of the 1063 professionals who responded to the questionnaire, 663 were men (62.4\%) and 400 were women $(37.6 \%)$. The distribution by area of knowledge is described in Table 1 . According to the number of years of research experience, the distribution was as follows: $36.6 \%$ had more than 20 years; $30.8 \%$ from 11 to 20 years; $18.3 \%$ from five to 10 years; and $14.4 \%$ less than five years.

\subsection{Creation and Reuse of Data}

\subsubsection{Existence of Data Management Policies}

The question regarding whether in the research projects in which the researcher has participated there was a data management policy or plan was answered as follows (Figure 1): the most frequent response was that "no data management policy or plan is available" $(54.9 \%) ; 24.5 \%$ replied that "there are units where data are stored for the use of the research group"; $27.8 \%$ of the respondents reported on "the existence of rules of anonymization and confidentiality policies"; "the existence of rules for the protection of intellectual property rights" came in at $20.1 \%$; and other responses, such as "there are authorization levels to access and modify data" and "data are deposited in external repositories or data banks", obtained percentages less than $20 \%$. 


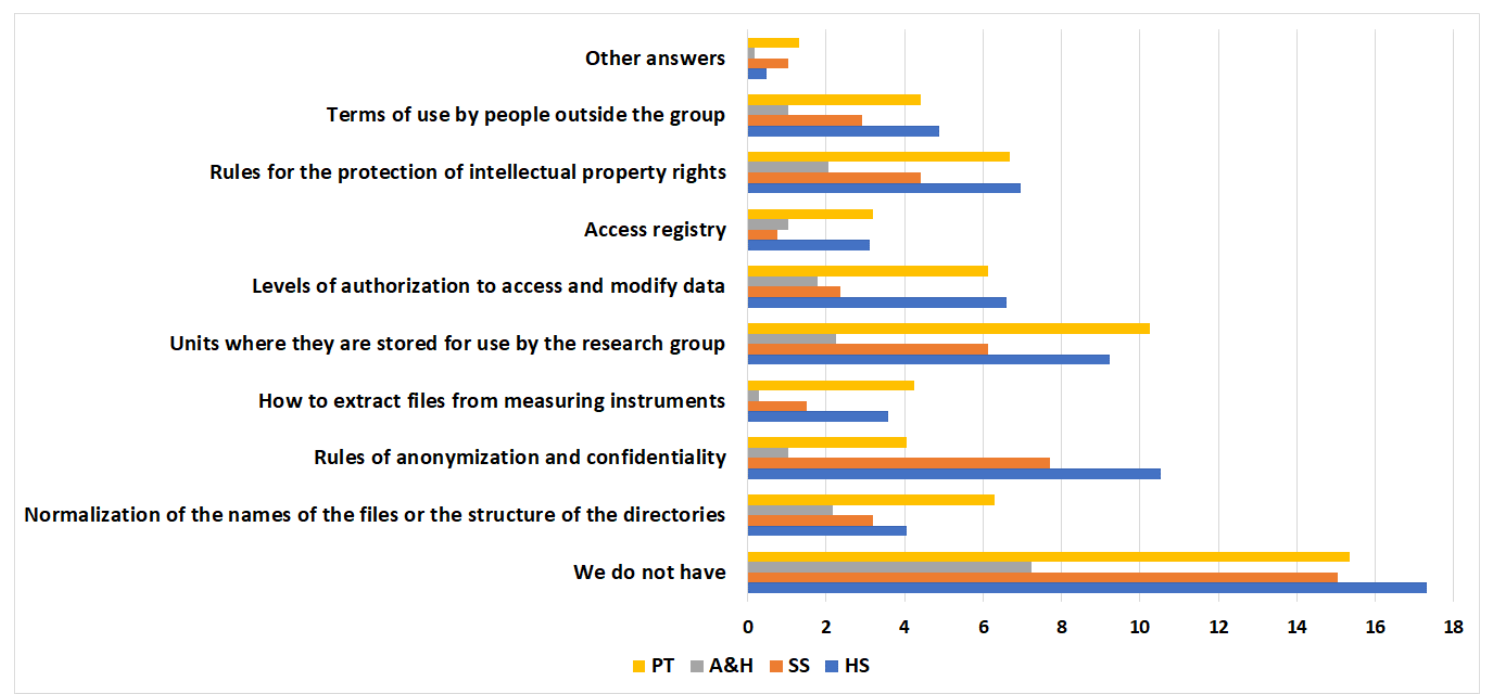

Figure 1. Existence of data management policies.

By area of knowledge, the most widespread response in all areas was the absence of a data management policy or plan. However, the second most common response in HS and SS was "the existence of rules of anonymization and confidentiality policies", while in PT and AH it was "the existence of units where data are stored for the use of the research group".

\subsubsection{Reasons for Developing the Data Policy}

The most important reasons for developing data policy differed from area to area (Figure 2). The most frequent responses in HS were "requirement of the financing entity of the project", followed by "absence of an institutional data management policy". In SS, if we exclude "other answers", the most frequent responses were "one day we lost all the data or we cannot use the data from old projects for lack of software or hardware", followed by "requirement of the financing entity of the project". In $\mathrm{AH}$, the responses were "complexity or volume of data associated with the project" and "absence of an institutional data management policy". Finally, the most frequent responses in PT were "one day we lost all the data ... " and "size of the project team". 


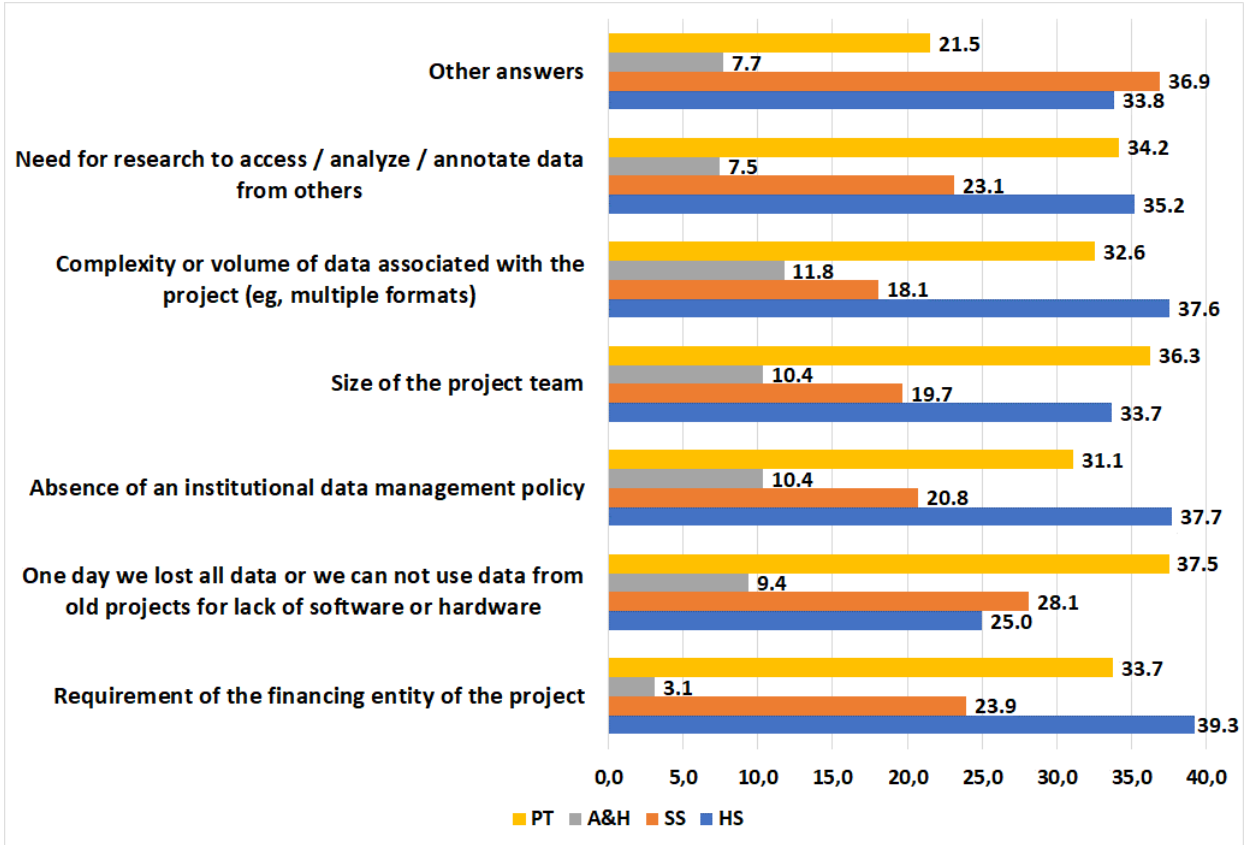

Figure 2. Reasons for developing the data policy.

\subsubsection{Devices Usually Used for Data Storage}

In this case, the answers were on researchers' local computers or on instruments or sensors $(81.5 \%)$, followed by portable storage units (such as USB sticks or DVDs) (53\%), institutional network servers $(24.2 \%)$, and external storage services (cloud) (23.7\%) (Figure 3).

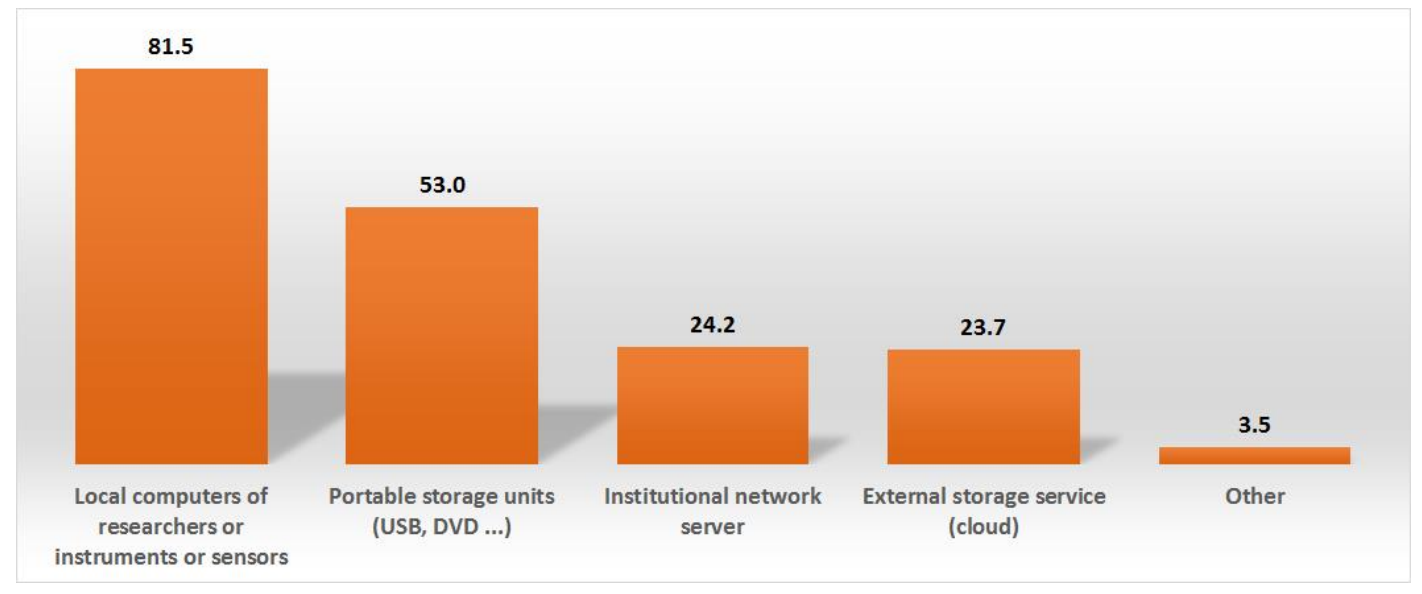

Figure 3. Devices usually used for data storage.

\subsubsection{Sources Used to Locate and Access Other Researchers' Data}

The answer "contact with colleagues" was the most frequent choice in all groups for years of research, followed by "general search engines (Google, Yahoo, etc.)". This second option was more frequent among researchers who had been researching for less than 5 years than in the other groups. It is striking that one of the least popular options was "documentation or archive centers (World Data Center, DANS, National Archives...)". With respect to area of knowledge, "I do not use data from others" was the most frequent option in HS and SS. In HS, this was followed by "additional material associated with the article on the platforms of the journals", while in SS it was followed by "institutional database and search utilities". In AH, if we exclude "other responses", the most frequent 
were "websites of authors/research groups" and "general search engines", and the same answers predominate in PT (Figure 4).
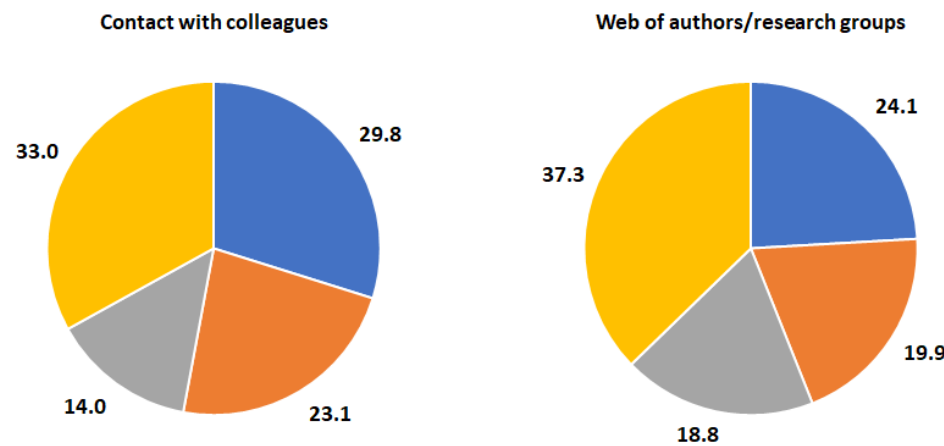

Institutional database and search utilities

General search engines (Google, Yahoo, ...)
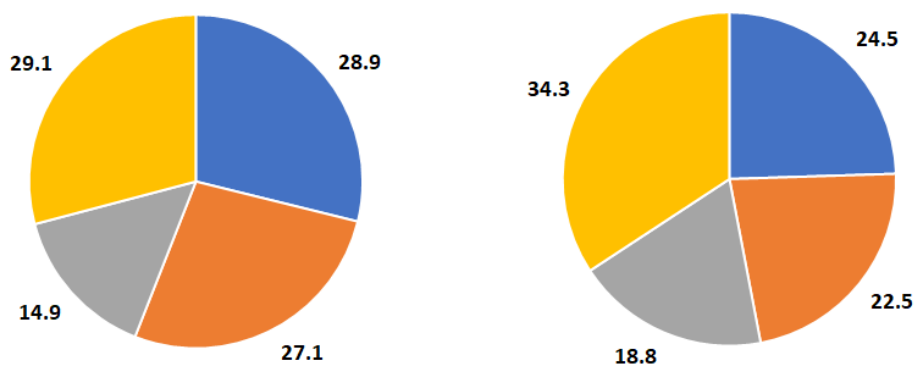

Documentation centers or archives (World Data Center, DANS, National Archives ...)

Additional material associated with the article in the platforms of the journals
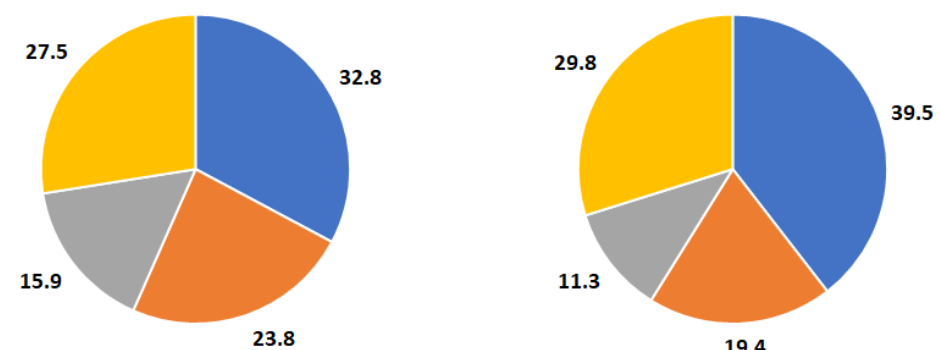

19.4

Not applicable (I do not use data from others)

Other responses
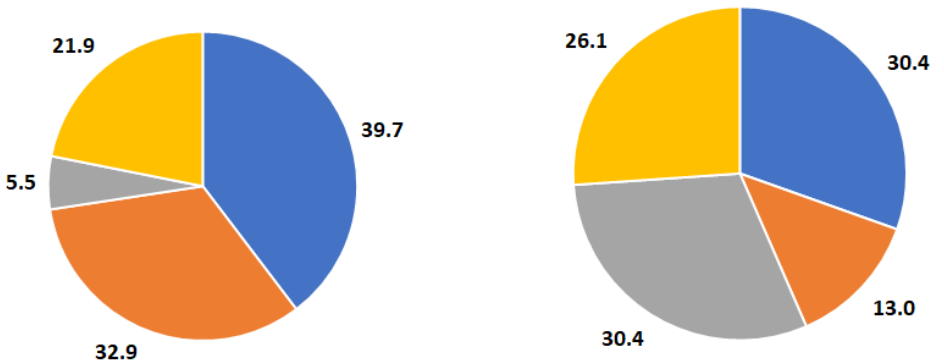

a Health Sciences $\quad$ Social Sciences Arts \& Humanities Physics \& Technology

Figure 4. Sources used to locate and access other researchers' data. 


\subsubsection{Data Availability}

When asked "Would you like to use research data from other researchers with whom you do not collaborate?" Most respondents in all groups said they would, with percentages close to $90 \%$ among junior researchers and somewhat lower among senior researchers. When asked "Do you currently use unpublished research data from other researchers with whom you do not collaborate?", most respondents (59.9\%) stated "my data are available to my research group and research collaborating colleagues". The other responses obtained much lower percentages: $18.5 \%$ for the response "I do not share my data, but I would like to do so in the future"; $15.1 \%$ for the response "my data are open to everyone"; and $10.9 \%$ for the response "my data may be available with appropriate changes (e.g., anonymous clinical data or with the obligation to cite them)". Only $5.4 \%$ responded that they did not share their data and did not want to do so in the future.

\subsubsection{Fears about Sharing}

The question "What worries you when sharing data in an external service?" obtained the following answers, in descending order (Figure 5): 47.9\% claimed "legal questions: confidentiality and intellectual property rights"; a percentage close to the previous one, $42.7 \%$, stated "misuse or interpretation of data"; the answer "loss of authorship" worried $28.7 \%$ of the respondents; concerns about "wasting time making them available" worried $27.8 \%$; and $24.3 \%$ responded "fear of losing the lead in research". The most frequent responses in all areas apart from AH were also "legal issues" and "misuse or interpretation of data". In HS and SS, the third concern was "loss of authorship", while in AH and PT, it was "wasting time making data available".

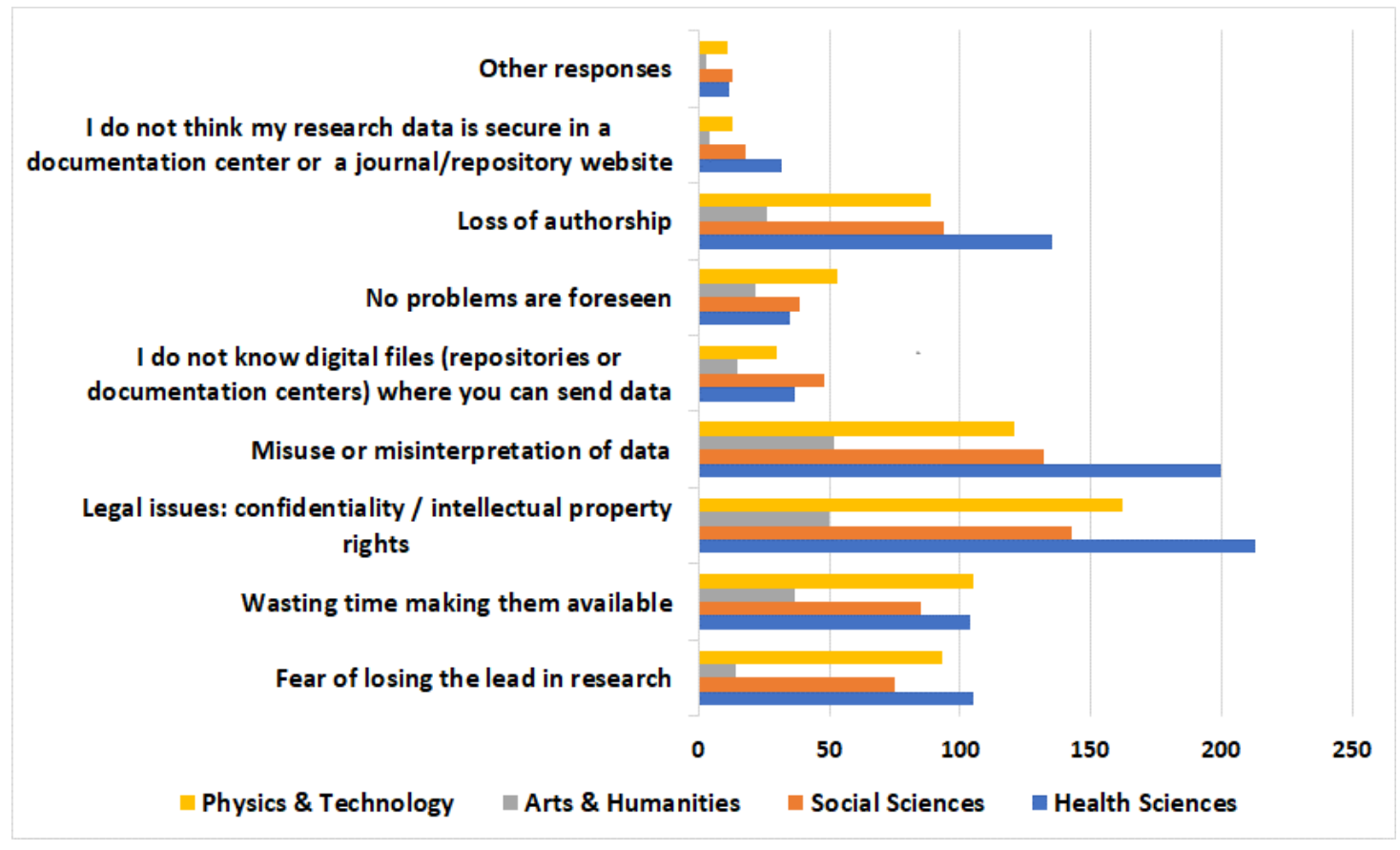

Figure 5. Fear of sharing research data.

\subsection{Preservation of Data}

The questions in this Section asked about the threats perceived by researchers related to their research data.

Most respondents in all areas did not consider it a threat that "users may be unable to understand or use the data (e.g., semantics, formats, or algorithms needed to use the data)". They also did not consider "the lack of sustainable computer software, hardware, or support" to be a threat, nor that 
"the origin and authenticity of the data may be uncertain". However, "restrictions on access and use of data for intellectual property reasons", "the loss of ability to locate data", and the fact that "the current custody of the data, in an organization or project, may cease to exist at some point in the future" were considered threats (Figure 6).

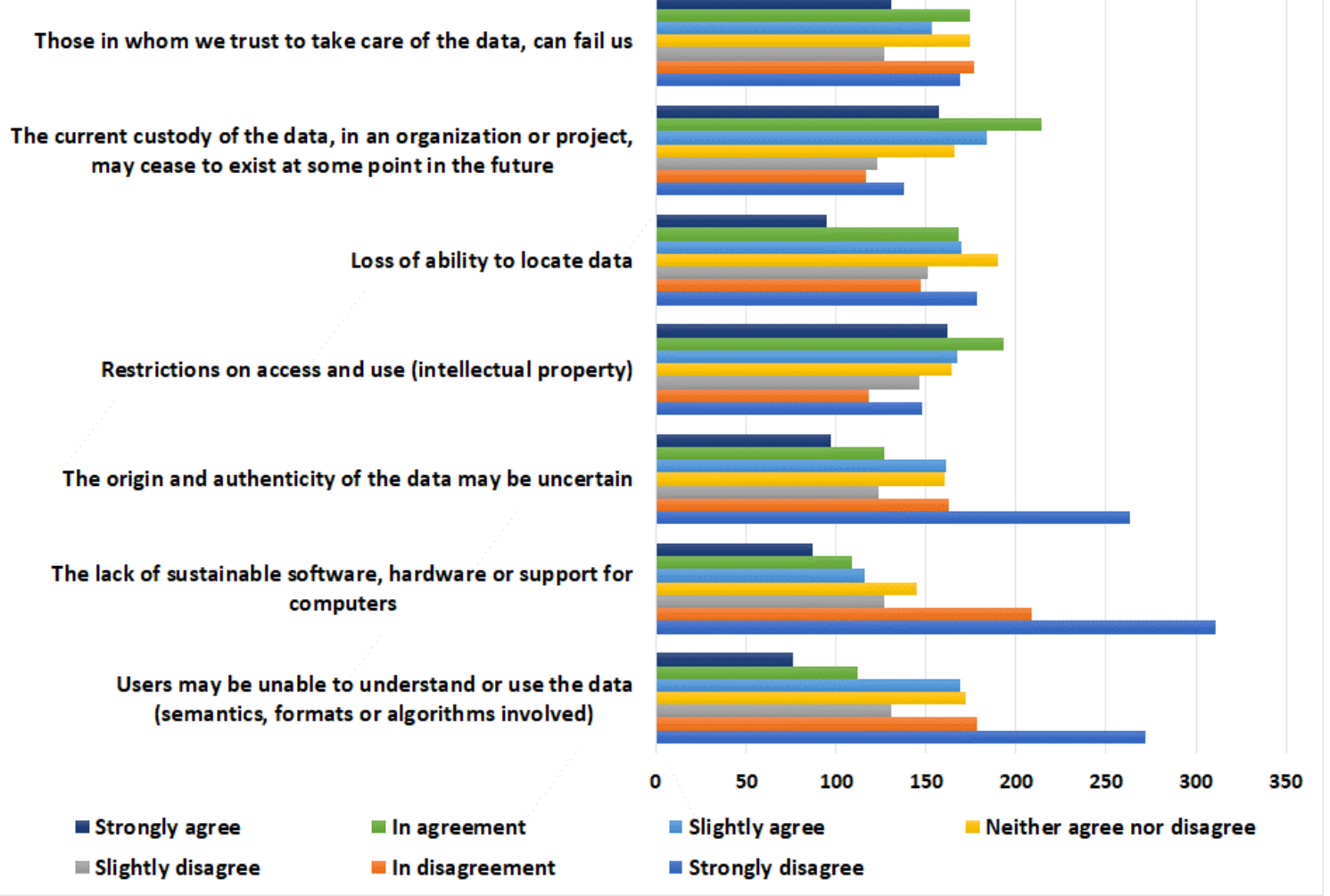

Figure 6. Key threats to data sharing.

With respect to subject area, access and use restrictions, and loss of ability to locate data were of particular concern to HS, SS, and PT researchers. Data safekeeping was a concern in all areas, but less so in $\mathrm{AH}$. The concern about trust in the data custodian showed mixed results but was more of a concern in HS.

In the topics concerning data preservation, it is interesting to know how research data are stored to preserve their future access and use. When asked "Where do you think it is most appropriate for research data to be preserved and shared?", the answers were clearly different from the previous question, with personal computers receiving approval from only $1.7 \%$ of respondents. More than half of the respondents indicated that the organization's repository was the appropriate place (56.6\%), a quarter responded as an attachment to a scientific article published by a journal, and a quarter stated "in an external service specialized in my discipline". Only 17\% preferred to preserve and share data through an external service specializing in generalist data.

With regard to the existence of data storage infrastructure, $87 \%$ of respondents indicated that they were unaware of their existence, compared with $10.7 \%$ who indicated that they were aware of their existence. The results were the same when researchers were asked who provided guidelines or recommendations for preserving data in their discipline, as researchers did not know, although some of them believed that this information should be provided by scientific societies and professional associations.

Another set of questions inquired about the reasons for preserving the data, with the following potential responses (Figure 7): (a) If the research is publicly funded, the results should become public property and, therefore, be properly preserved; (b) it stimulates the advancement of science based on 
existing knowledge; (c) it serves to validate investigations; (d) it allows the re-analysis of existing data; (e) it can stimulate interdisciplinary collaborations; (f) it has potential economic value; and (g) data are unique and irreplaceable. Most researchers responded positively to these statements. The evaluation was more positive (strongly agree) for the first four assertions, while the assertions referring to "the potential economic value of the data" and "data are unique and irreplaceable" obtained a lower evaluation (disagreement).

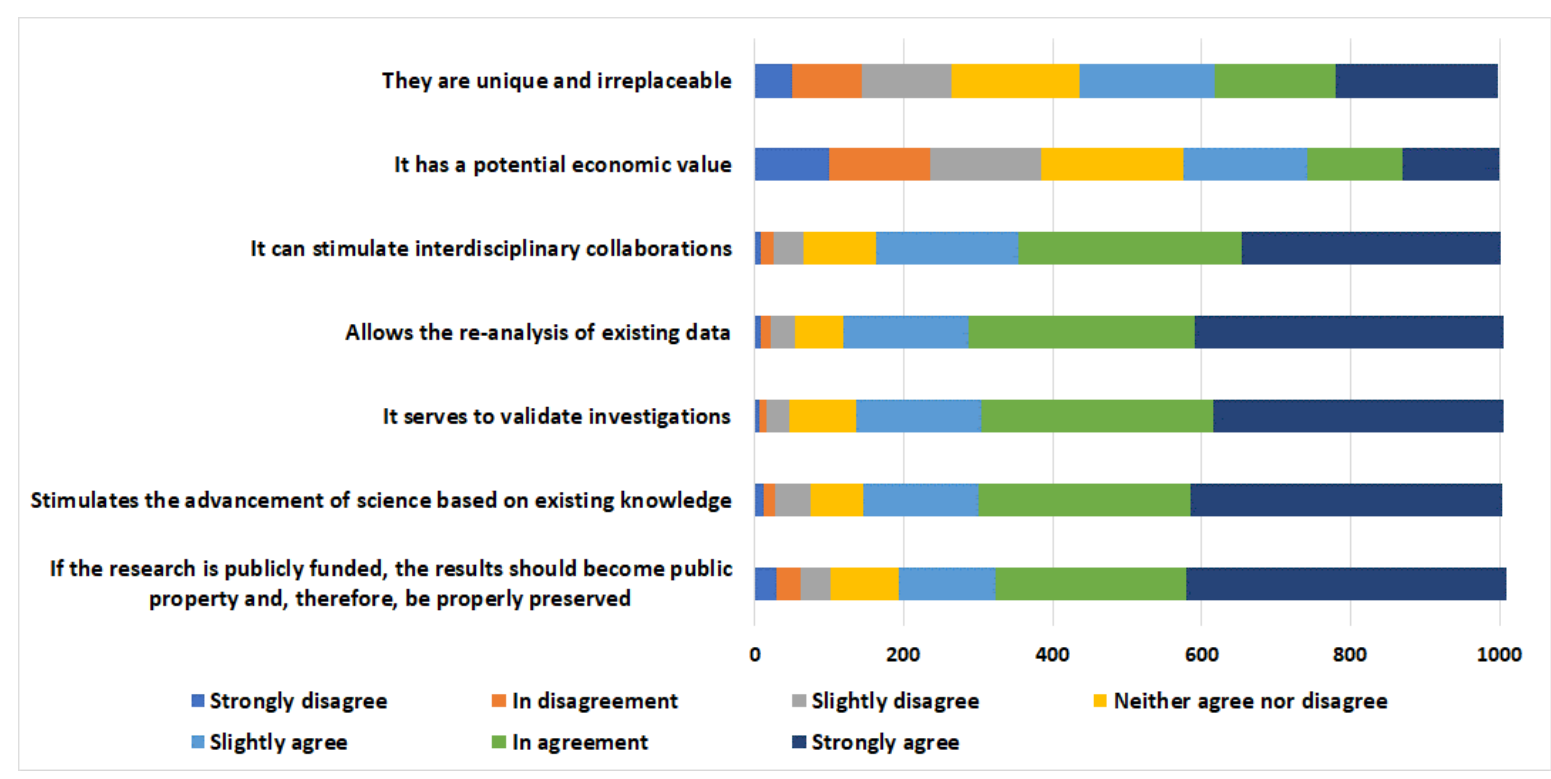

Figure 7. Reasons for preservation of data.

\section{Discussion}

This survey provides an assessment of data-sharing perceptions and practices from a sample of 1063 Spanish researchers in several scientific areas, including the barriers and enablers that could be considered in improving the open data system. Through this understanding of the barriers and concerns preventing scientists from being willing to publish their data, policy makers and managers of data could design open data systems to provide adequate infrastructure, policies, and best practices that would help to promote global data sharing and to build researchers' confidence in this practice $[8,14]$. It is essential to highlight that the development of open access to research data is influenced not only by new methods, management structures, and technologies but also by the human aspect. The willingness and attitude of the researchers and owners of the data with respect to participating in the creation of this global network through the exchange of data are crucial for its development and maintenance. It is based on these assumptions that this survey is framed.

\subsection{Literature Review and Comparison with Other Studies}

Our survey has common features when compared to other studies that pointed out that researchers have the upper hand in deciding to release or withhold data for various reasons, such as the time needed to prepare the data for sharing, lack of resources, reputation, or financial concerns $[8,15,25]$. In a mailed survey of geneticists and other scientists at the 100 US universities that received the most funding from the National Institutes of Health in 1998, 83\% of respondents reported that it required too much effort to produce materials for sharing and $53 \%$ that they were protecting their own ability to publish [26]. However, Smith and Roberts [3] argue against all these impediments and indicate that, since in the health sciences data are often provided by patients on a disinterested basis, it would be unethical for them to be the property of individual researchers to use to advance their careers, and they should be available for the wider scientific community. 
Our results have also some similarities with a study commissioned by the Wellcome Trust that investigated the attitudes and behavior of 583 researchers towards data sharing. In this study, $50 \%$ of researchers made research data available, usually through institutional repositories; $25 \%$ of researchers had never reused existing data; data for reuse were obtained from colleagues, repositories, or directly from the creator; and the main reasons for making the data available were the requirements of funders and journals, as these are considered to be good research practices, to facilitate collaboration and to facilitate validation and duplication of data [24].

Some of the results of this survey are in line with those found in other studies. Aitken et al. [27], in a systematic review of sharing health data for research, conclude that there are low levels of knowledge of current practices and uses of the data and point to the need for greater awareness among all stakeholders, combined with public deliberation on data sharing. Levin et al. [28] conducted in UK an analysis of in-depth interviews to researchers in biology and bioinformatics and identified some core themes that characterize researchers' understanding of openness in science, including "the existence of repositories for data, software, and models to carry it out; the competitiveness of academic fields; the digital nature of research; the credit system; career structures in academic research; collaborations with industrial partners and attempts at commercialization; and guidelines for intellectual property" [28]. They conclude that it is necessary to take into account the diversity and contextual nature of openness in policies and recommendations, given the heterogeneity of data formats, sizes, standards, and repositories. For example, adopting open data policies that are too rigorous may have negative effects on scientific research by forcing scientists to disclose results and resources in ways that they deem useless or inappropriate or by requiring openness at a stage of research where it is more likely to hamper than encourage progress [28]. In the study commissioned by the Wellcome Trust, the main incentives to make more data available in the future are funding to cover the cost of data preparation, enhancement of academic reputation, knowing how others will use the data and data sharing being taken into account in future funding and career promotion decisions [24]. In the same study, $47 \%$ indicated the need for data storage support, $57 \%$ for technical support, and $51 \%$ for data management support.

One of the most discussed topics in the literature is the barriers to data sharing and action measures to overcome them $[8,29,30]$. In a systematic review of barriers to data sharing in public health, up to 20 barriers were classified as technical, motivational, economic, political, legal, and ethical [30]. The researchers who responded to our survey essentially agree with those in other studies in pointing out three concerns: that the legal and intellectual property aspects are regulated; the fear that others will misinterpret the data and that this will prejudice them; the concern that other researchers will publish the results sooner. These opinions are repeated in practically all areas of knowledge. The technical, economic, and motivational barriers depend on solving other challenges in the research system, while the political, ethical, and legal barriers require other approaches of consensus among all those involved in the research system. A similar classification has been offered in another study, emphasizing the critical challenges facing individual researchers in publishing their research data openly and the extent to which these challenges influence the propensity of researchers to openly share their data sets. This study found two key determinants that affect researchers' willingness to publish their data. The first is processes related to data management (management skills and organizational support). The second is the legal recognition of authorship for the producer of the data set [8]. In the study commissioned by the Wellcome Trust, the main perceived barriers to sharing data were fear of misuse or misinterpretation, fear of losing publication opportunities, and time and effort to prepare and deposit data [24]. Ultimately, one of researchers' concerns is the fear that other researchers using the data will find procedural errors, different results, or omissions in the original work that would undermine their work $[8,31,32]$, although this could largely be avoided by ensuring the quality of the data.

It has been observed that most obstacles to data sharing tend to be mainly related to technical and organizational issues, in line with what has been found in other studies [33,34]. Therefore, 
many obstacles could be remediable with some interventions, such as providing researchers with additional resources to disseminate their research results after publication [26].

Another important topic that warrants attention is the need for recognition. The survey results commissioned by the Wellcome Trust showed that $90 \%$ of respondents agreed on the importance of recognizing data providers. Recognition could take many forms: collaboration, co-authorship, formal recognition, and appropriate citation [8].

On the other hand, there is an urgent need to define the legal aspects related to the authorship or intellectual ownership of data and respect for privacy when dealing with sensitive material. In the opinion of the respondents, the official bodies should be the driving force behind this movement and the creation of the necessary infrastructure.

\subsection{Concluding Remarks}

This study provides a preliminary analysis of the determinants of the likelihood that Spanish researchers will publish their research data. The study of how Spanish researchers are sharing their data completes the landscape that is being drawn with surveys in other countries such as Austria [35,36] or in institutions already mentioned above. In this way, the data generated by Spanish research contributes to achieving the target postulated in objective 9.5 "Enhance scientific research, upgrade the technological capabilities of industrial sectors in all countries, [ ... ] encouraging innovation".

The analysis identified three key determinants of the sharing of research data sets: first, the importance of developing technological and organizational tools to provide support to ensure the open publication of data; second, the importance of the formal recognition of data owners through opportunities for collaboration, formal recognition, and proper citation; third, the need for legal regulations and policies to support data reuse and attribution.

From the analysis of the results, it emerges that it is necessary to design and carry out awareness-raising campaigns aimed at professionals regarding the publication of their research data, but it is also necessary to create infrastructure to facilitate long-term data storage and conservation. Training campaigns in the culture of data sharing would also be desirable. There is also an urgent need to define the legal aspects related to authorship or intellectual ownership of data and respect for privacy when dealing with sensitive material. In the opinion of those surveyed, official bodies should be the driving force behind this movement and the creation of the necessary infrastructure.

Several implications can be deduced from the results of this work. One of them is the difficulties that researchers have when preparing their data, as they are unaware of the repositories that exist and their requirements, such as, for example, the types of metadata that must complement the data. Another implication is that for researchers, appreciation and acknowledgement are significant factors affecting their sharing behavior. Policies are needed to ensure appropriate recognition of the creator of the data and of those who are responsible for the reuse of the data and to take factors such as reputation into consideration [8]. Finally, as long as there is no legal obligation to deposit data, it is the researchers who have in their hands the decision to share their data or not, as well as what type and amount of data they will deposit.

All institutions involved in data sharing should work together to help researchers assess and determine what materials should be deposited, how, and at what stage of the research process. Libraries and documentation centers could provide specialist assistance for the development of data management plans or data infrastructure [37]. Universities could advise researchers on ethical and legal issues related to intellectual property and privacy. Public bodies could finance data sharing and encourage it by recognizing it as a research merit [8,28,37-39].

Researchers need to acquire minimal data management skills to be able to publish data openly. These data management skills are a significant predictor of data repositories or dedicated websites [8]. The development and preparation of quality data for publication is closely related to the incentives for researchers to carry out data sharing [8]. For some authors, the bottlenecks in data sharing occur due to the need to harmonize all topics related to data sharing [33,34]. 


\subsection{Limitations and Future Research}

This study attempts to provide a preliminary assessment of the determinants of Spanish researchers' motivation to share data sets. As a preliminary assessment, this study recognizes several limitations that require future research. First, this study is based on the assumption that researchers have the freedom to decide whether to publish their raw research data, regardless of whether they are mandated to do so by their institutions or by the journals in which they published their research. Future research could identify whether there are differences in results between these cases. Second, we did not separately analyze and compare the responses of researchers who receive rewards for data sharing from those who do not, so future surveys may consider including this factor in the questionnaire. Third, the authors acknowledge that more research is needed to globally generalize these findings.

Supplementary Materials: The following are available online at http://www.mdpi.com/2306-5729/5/2/29/s1.

Author Contributions: All authors contributed to conceptualizing and designing the study. A.V.-I. and A.A.-A. performed data analysis and visualizations. F.P. and A.F.S. curated data. R.A.-B., A.V.-I. and A.A.-A. studied findings. A.V.-I. and A.A.-A. interpreted the data. R.A.-B. and A.F.S. drafted the first version of the manuscript. R.A.-B. and A.V.-I. commented for important intellectual content and made major revisions. All authors meet the ethical criteria for authorship. R.A.-B. accept full responsibility for the finished manuscript and controlled the decision to publish. All authors have read and agreed to the published version of the manuscript.

Funding: This research was funded by National R+D+I of the Ministry of Economy and Competitiveness of the Spanish Government (projects: CSO2012-39632-C02-01 and CSO2015-65594-C2-2-R) and the 2015-Networks of Excellence Call (project CSO2015-71867-REDT). The APC was not funded.

Conflicts of Interest: The authors declare no conflict of interest.

\section{References}

1. Alsheikh-Ali, A.A.; Qureshi, W.; Al-Mallah, M.H.; Ioannidis, J.P.A. Public availability of published research data in highimpact journals. PLoS ONE 2011, 6, 24357. [CrossRef] [PubMed]

2. Piwowar, H.A.; Chapman, W.W. Public sharing of research datasets: A pilot study of associations. J. Informetr. 2010, 4, 148-156. [CrossRef] [PubMed]

3. Smith, R.; Roberts, I. Time for sharing data to become routine: The seven excuses for not doing so are all invalid. F1000Research 2016, 5, 781. [CrossRef] [PubMed]

4. Gotzsche, P.C. Strengthening and opening up health research by sharing our raw data. Circ. Cardiovasc. Qual. Outcomes 2012, 5, 236-237. [CrossRef] [PubMed]

5. González, L.M.; Saorín, T.; Ferrer, A.; Aleixandre-Benavent, R.; Peset, F. Gestión de datos de investigación: Infraestructuras para su difusión. Prof. Inf. 2013, 22, 414-423. [CrossRef]

6. Guttmacher, A.E.; Nabel, E.G.; Collins, F.S. Why data-sharing policies matter. Proc. Natl. Acad. Sci. USA 2009, 106, 16894. [CrossRef]

7. Gurin, J.; Manley, L.; Ariss, A. Sustainable Development Goals and Open Data. World Bank. 2015. Available online: https://blogs.worldbank.org/digital-development/sustainable-development-goals-and-open-data (accessed on 6 February 2019).

8. Sayogo, D.S.; Pardo, T.A. Exploring the determinants of scientific data sharing: Understanding the motivation to publish research data. Gov. Inf. Q. 2013, 30, S19-S31. [CrossRef]

9. Murray-Rust, P. Open Data in Science. Available online: http://hdl.handle.net/10101/npre.2008.1526.1 (accessed on 6 February 2019).

10. Molloy, J.C. The open knowledge foundation: Open data means better science. PLoS Biol. 2011, 9, 1001195. [CrossRef]

11. Pisani, E.; AbouZahr, C. Sharing health data: Good intentions are not enough. Bull. WHO 2010, 88, 462-466. [CrossRef]

12. Krumholz, H.M. Open science and data sharing in clinical research: Basing informed decisions on the totality of the evidence. Circ. Cardiovasc. Qual. Outcomes 2012, 5, 141-142. [CrossRef]

13. Rodriguez, V. Access to data and material for research: Putting empirical evidence into perspective. New Genet. Soc. 2009, 28, 67-86. [CrossRef] 
14. Tenopir, C.; Allard, S.; Douglass, K.; Aydinoglu, A.U.; Wu, L.; Read, E.; Manoff, M.; Frame, M. Data sharing by scientists: Practices and perceptions. PLoS ONE 2011, 6, 21101. [CrossRef]

15. Chalmers, D.R.; Nicol, D.; Otlowski, M.F. To share or not to share is the question. Appl. Transl. Genom. 2014, 3, 116-119. [CrossRef] [PubMed]

16. Gharesifard, M.; When, U. To share or not to share: Drivers and barriers for sharing data via online amateur weather networks. J. Hydrol. 2016, 535, 181-190. [CrossRef]

17. Satinsky, E.; Driessens, C.; Crepaz-Keay, D.; Kousoulis, A.A. Mental health service users' perceptions of data sharing and data protection: A short qualitative report. J. Innov. Health Inform. 2018, 25, 239-242. [CrossRef]

18. Data Asset Framework Implementation Guide. Available online: https://www.data-audit.eu/docs/DAF_ Implementation_Guide.pdf (accessed on 6 February 2019).

19. Ekmekcioglu, C.; Rice, R. Edinburgh Data Audit Implementation Project Final Report 2009. Available online: http://repository.jisc.ac.uk/283/1/edinburghDAFfinalreport_version2.pdf (accessed on 6 February 2019).

20. McGowan, T.; Gibbs, T.A. Southampton Data Survey: Our Experiences \& Lessons Learned 2009. University of Southampton: UK. Available online: http://www.disc-uk.org/docs/SouthamptonDAF.pdf (accessed on 6 February 2019).

21. PARSE. Insight 2010. Insight into digital preservation of research output in Europe. Available online: https://libereurope.eu/wp-content/uploads/2010/01/PARSE.Insight.-Deliverable-D3.4-Survey-Report. -of-research-output-Europe-Title-of-Deliverable-Survey-Report.pdf (accessed on 6 February 2019).

22. Simukovic, E.; Kindling, M.; Schirmbacher, P. Humboldt-Universität zu Berlin Research Data Management Survey Results. ZENODO-Repository. 2013. Available online: https://zenodo.org/record/7468 (accessed on 6 February 2019).

23. Australian National University. Managing Digital Research Data at the Australian National University. 2016. Available online: https://services.anu.edu.au/files/DataManagement.pdf (accessed on 6 February 2019).

24. Van Den Eynden, V.; Knight, G.; Vlad, A.; Radler, B.; Tenopir, C.; Leon, D.; Manista, F.; Whitworth, J.; Corti, L. Survey of Wellcome Researchers and their Attitudes to Open Research. Wellcome Trust. 2016. Available online: https://dx.doi.org/10.6084/m9.figshare.4055448 (accessed on 5 February 2019).

25. Aitken, M.; de St Jorre, J.; Pagliari, C.; Jepson, R.; Cunningham-Burley, S. Public responses to the sharing and linkage of health data for research purposes: A systematic review and thematic synthesis of qualitative studies. BMC Med. Ethics 2016, 17, 73. [CrossRef]

26. Campbell, E.G.; Clarridge, B.R.; Gokhale, M.; Birenbaum, L.; Hilgartner, S.; A Holtzman, N.; Blumenthal, D. Data withholding in academic genetics-Evidence from a national survey. JAMA 2002, 287, 473-480. [CrossRef]

27. Levin, N.; Leonelli, S.; Weckowska, D.; Castle, D.; Dupré, J. How Do Scientists Define Openness? Exploring the Relationship between Open Science Policies and Research Practice. Bull. Sci. Technol. Soc. 2016, 36, 128-141. [CrossRef]

28. Pampel, H.; Dallmeier-Tiessen, S. Open Research Data: From Vision to Practice. Available online: http: //book.openingscience.org.s3-website-eu-west-1.amazonaws.com/vision/open_research_data.html (accessed on 4 March 2019).

29. Van Panhuis, W.; Paul, P.; Emerson, C.; Grefenstette, J.J.; Wilder, R.; Herbst, K.; Heymann, D.L.; Burke, D.S. A systematic review of barriers to data sharing in public health. BMC Public Health 2014, 14, 1144. [CrossRef]

30. Koslow, S.H. Sharing primary data: A threat or asset to discovery? Nat. Rev. Neurosci. 2002, 3, 311-313. [CrossRef]

31. Park, Y.; Greene, C.S. A parasite's perspective on data sharing. Gigascience 2018, 7, 129. [CrossRef] [PubMed]

32. McGuire, A.L.; Basford, M.; Dressler, L.G.; Fullerton, S.M.; Koenig, B.A.; Li, R.; Mccarty, C.A.; Ramos, E.; Smith, M.E.; Somkin, C.P.; et al. Ethical and practical challenges of sharing data from genome-wide association studies: The eMERGE Consortium experience. Genome Res. 2011, 21, 1001-1007. [CrossRef] [PubMed]

33. Joly, Y.; Dove, E.S.; Knoppers, B.M.; Bobrow, M.; Chalmers, D. Data sharing in the post-genomic world: The experience of the International Cancer Genome Consortium (ICGC) Data Access Compliance Office (DACO). PLoS Comput. Biol. 2012, 8, e1002549. [CrossRef] [PubMed]

34. Bauer, B.; Ferus, A.; Gorraiz, J.; Gründhammer, V.; Gumpenberger, C.; Maly, N.; Mühlegger, J.M.; Preza, J.L.; Sánchez Solís, B.; Schmidt, N.; et al. Researchers and Their Data. Results Of An Austrian Survey—Report 2015. Zenodo. 2015. Available online: https://doi.org/10.5281/ZENODO.34005 (accessed on 15 December 2019). 
35. Peters, I.; Kraker, P.; Lex, E.; Gunpenberger, C.; Gorraiz, G. Research data explored: An extended analysis of citations and altmetrics. Scientometrics 2016, 107, 723-744. [CrossRef] [PubMed]

36. Leonelli, S.; Spichtinger, D.; Prainsack, B. Sticks and carrots: Incentives for a meaningful implementation of open science guidelines. Geo 2015, 2, 12-16.

37. Kaye, J.; Heeney, C.; Hawkins, N.; Boddington, P. Data sharing in genomics-re-shaping scientific practice. Nat. Rev. Genet. 2009, 10, 331-335. [CrossRef]

38. Nuffield Council on Bioethics. The Collection, Linking and Use of Data in Biomedical Research and Health Care: Ethical Issues. 2015. Available online: http://nuffieldbioethics.org/wp-content/uploads/Biological_ and_health_data_web.pdf (accessed on 7 February 2019).

39. The BRIF Workshop Group; Andrieu, S.; Bertier, G.; Boeckhout, M.; Cambon-Thomsen, A.; Carpenter, J.; Dagher, G.; Dalgleish, R.; Deschênes, M.; Di Donato, J.H.; et al. The role of a Bioresource Research Impact Factor as an incentive to share human bioresources. Nat. Genet. 2011, 43, 503-504.

(C) 2020 by the authors. Licensee MDPI, Basel, Switzerland. This article is an open access article distributed under the terms and conditions of the Creative Commons Attribution (CC BY) license (http://creativecommons.org/licenses/by/4.0/). 